\title{
Metastatic pulmonary calcification after renal transplantation
}

\author{
M. Murris-Espin*, L. Lacassagne*, A. Didier*, J.J. Voigt**, J.M. Cisterne+, \\ J. Giron++, D. Durand+, P. Leophonte*
}

Metastatic pulmonary calcification after renal transplantation. M. Murris-Espin, L. Lacassagne, A. Didier, J.J. Voigt, J.M. Cisterne, J. Giron, D. Durand, P. Leophonte. (c)ERS Journals Ltd 1997.

ABSTRACT: Metastatic pulmonary calcifications, unlike dystrophic calcifications, occur in the normal healthy lung. The radiological pattern is quite specific. The disease is commonly described in chronic renal failure with calcium disorders. The prognosis is totally unpredictable.

In 1992, a 50 yr old man underwent a successful renal transplantation during the final stage of chronic renal failure. He subsequently developed asymptomatic diffuse nodular opacities, that were discovered in 1995. An open lung biopsy confirmed the diagnosis of metastatic pulmonary calcification. There was no calcium disorder in this patient.

In contrast to the benign course of pulmonary calcification in most patients, some fulminant pulmonary calcifications complicating renal transplantation or hypercalcaemia have been described. Radiographic identification of such entities is important to permit correction of calcium disorders. Otherwise, the condition is a potentially progressive and fatal cause of respiratory failure.

Eur Respir J 1997; 10: 1925-1927.
*Service de Pneumologie-Allergologie, and +Service de Néphrologie, Hôpital de Rangueil, Toulouse, France. **Service d'Anatomie Pathologique, and ${ }^{++}$Service de Radiologie, Hôpital de Purpan, Toulouse, France.

Correspondence: M. Murris-Espin Service de Pneumologie-Allergologie Hôpital de Rangueil 31054 Toulouse France

\section{Keywords: Lung} metastatic calcification renal transplantation

Received: November 251996 Accepted after revision April 171997
Soft tissue calcification usually occurs when tissue is damaged or in the presence of calcium disorders. We report the case of a man who, following kidney transplantation, developed diffuse confluent nodular opacities, visible on chest radiography, without any clinical symptoms. The computed tomography (CT) scan revealed the presence of calcifications.

\section{Case report}

A $50 \mathrm{yr}$ old man developed progressive renal failure as a result of nephropathic interstitial disease. In May 1992, he underwent a thyroparathyroidectomy for secondary hyperparathyroidism. The surgical specimen demonstrated features consistent with intracapsular adenocarcinoma. He received a cadaveric renal transplant in November 1992, after 12 yrs of chronic haemodialysis. In the early post-transplant period, he showed slightly elevated parathormone levels, i.e. $135 \mathrm{ng} \cdot \mathrm{mL}^{-1}$ in May 1993, $118 \mathrm{ng} \cdot \mathrm{mL}^{-1}$ in November 1993, and $67 \mathrm{ng} \cdot \mathrm{mL}^{-1}$ in September 1994. Neither calcium nor phosphorus serum abnormalities occurred in the early or later posttransplant phases. Chest radiographs were normal. The patient was maintained on daily doses of cyclosporin (200 $\mathrm{mg})$, prednisolone $(15 \mathrm{mg})$, isradipine $(10 \mathrm{mg})$, atenolol and L-thyroxine. In March 1995, the chest radiograph revealed numerous diffuse confluent nodular opacities, 5-12 $\mathrm{mm}$ in diameter, with poorly-defined margins, predominantly in the upper lung zone (fig. 1). The patient was asymptomatic and the clinical examination was normal. He had no fever, pain, coughing or dyspnoea.

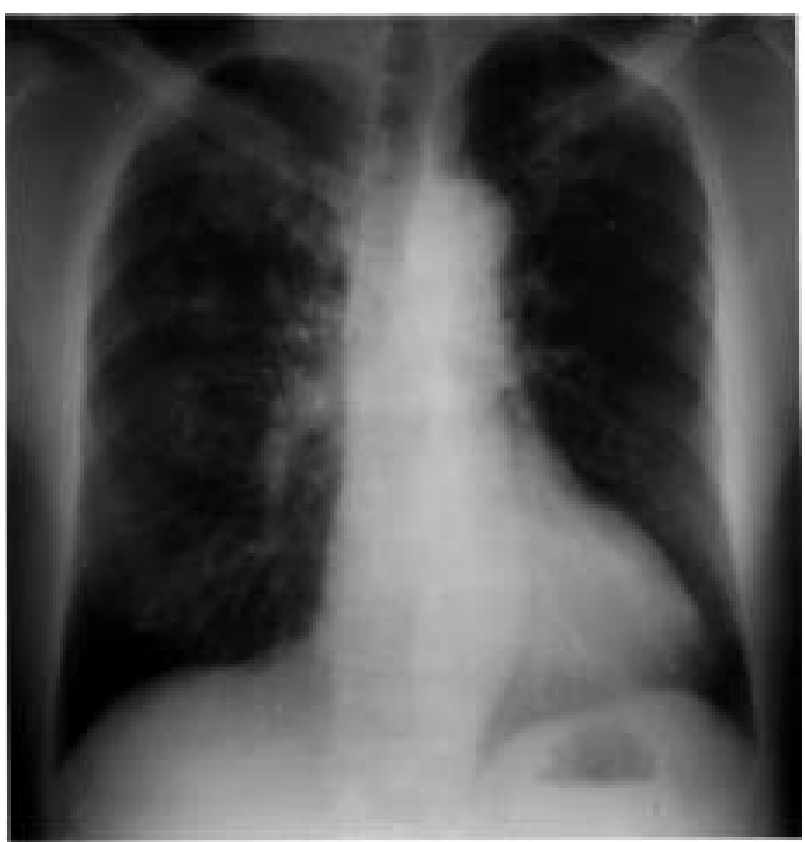

Fig. 1. - Chest radiograph showing numerous diffuse confluent nodular opacities, predominantly in the upper zone.

On the CT scan, the nodules appeared fluffy. Calcifications were observed in some of the nodules (fig. 2). The chest radiograph had been normal prior to transplantation.

The following serum levels were recorded (normal values in parentheses): calcium $9.2 \mathrm{mg} \cdot \mathrm{dL}^{-1}(9.0-10.2$ 


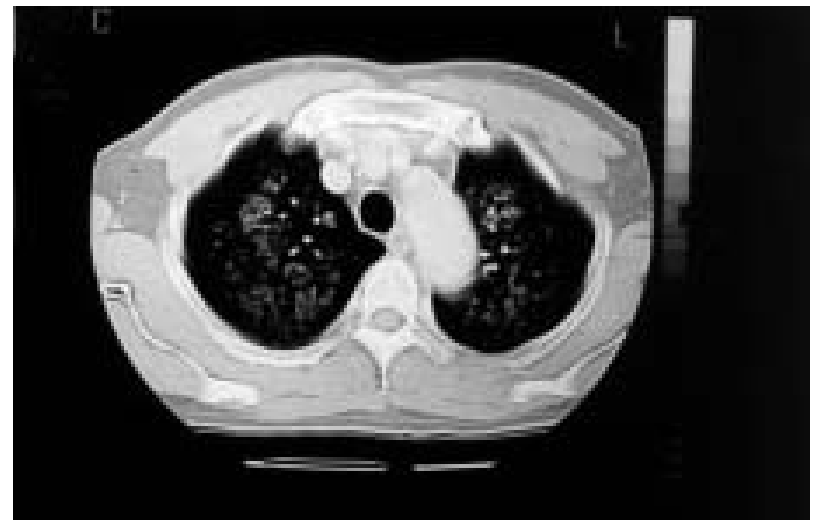

Fig. 2. - Computed tomography (CT) scan of the chest. Nodules are visible, fluffy, relatively poorly defined, and diffuse but predominantly in the upper lung area. Several are calcified.

$\left.\mathrm{mg} \cdot \mathrm{dL}^{-1}\right)$; phosphate $3.8 \mathrm{mg} \cdot \mathrm{dL}^{-1}\left(2.5-4.0 \mathrm{mg} \cdot \mathrm{dL}^{-1}\right)$; alkaline phosphatase 67 International Units (IU) (30-125 IU); creatinine $124 \mu \mathrm{mol} \cdot \mathrm{L}^{-1}$; urea $8.6 \mathrm{mmol} \cdot \mathrm{L}^{-1}(2.5-7.5$ $\left.\mathrm{mmol} \cdot \mathrm{L}^{-1}\right)$. Vitamin D level, parathormone level $(<50$ $\left.\mathrm{pg} \cdot \mathrm{mL}^{-1}\right)$, angiotensin-converting enzyme (ACE) and serum thyroglobulin concentrations were normal.

No serum antibodies against viruses (Myxovirus influenzae, respiratory synctial virus, Myxovirus parainfluenzae 1.2.3) or the usual pathogens (Chlamydia pneumoniae, Mycoplasma pneumoniae, Legionella pneumophila) were found. Bronchial and transbronchial biopsies were normal. Bronchoalveolar lavage was hypercellular (440 leucocytes $\cdot \mathrm{mm}^{-3}$ ). Differential count showed $90 \%$ macrophages, $9 \%$ lymphocytes $9 \%$ and $1 \%$ polymorphonuclear neutrophils. No intracellular or extracellular calcium crystals were found. There were no abnormal cells.

Lung function tests gave the following results: transfer factor of the lung for carbon monoxide $(T \mathrm{~L}, \mathrm{CO}) 9.5$ $\mathrm{mL} \cdot \mathrm{min}^{-1} \cdot \mathrm{mmHg}^{-1}(50 \%$ of predicted); vital capacity (VC) $2,300 \mathrm{~mL}(60 \%$ pred), forced expiratory volume in one second (FEV1) $1,500 \mathrm{~mL}$ (53\% pred); and total lung capacity (TLC) 3,600 mL (70\% pred). Neck ultrasonography was normal.

An open-lung biopsy was performed. Histological examination revealed calcium deposits in the alveolar septa and in the wall of the small arterioles (fig. 3).

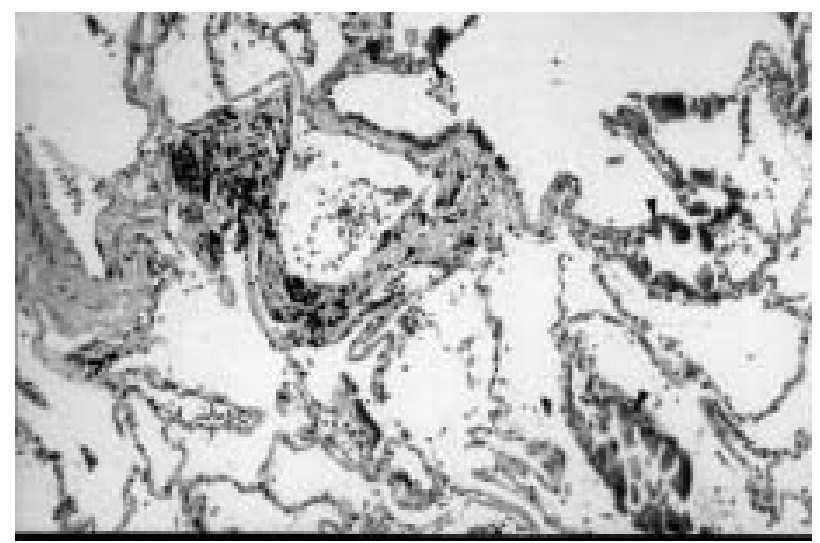

Fig. 3. - Histological aspect of the open-lung biopsy. Calcium deposits in the alveolar septa confirm the diagnosis of metastatic calcification. Internal scale bar $=200 \mu \mathrm{m}$.

\section{Discussion}

Metastatic pulmonary calcification is characterized by diffuse calcium salt deposition, whether localized in apical zones or throughout the lungs. It may be associated with myocardial calcification in chronic renal disease.

Although calcium is merely interstitial in location, the opacities observed radiographically may simulate airspace disease, such as pulmonary oedema or infarction (parenchymal opacification, poorly-defined infiltrates). Numerous nodular opacities measuring 2-12 mm in diameter are usually observed. Calcification is rarely identified on a conventional chest radiograph, and this low detectability may be related to the small size of the calcium deposits and the high kilovoltage radiographic technique [1]. The pulmonary nodules are more clearly defined on CT scan. They may be unilateral or diffuse but predominate in the upper zones. Calcifications of vessels of the chest wall are better seen on the mediastinal windows. Other findings on the CT scan include ground-glass attenuation and patchy consolidation [2]. Sometimes, only high resolution sections of CT scan disclose the calcified nature of the nodules [2]. A roentgenographic technique known as dual energy digital chest radiography may be useful in detecting lung calcifications [3]. Visible calcifications may remain stable for many years or may progress rapidly.

Metastatic calcifications of vital parenchyma are related to chronically elevated calcium levels as in chronic renal failure, primary hyperparathyroidism, D hypervitaminosis, milk alkali syndrome [2], or diffuse myelomatosis. Calcifications are usually composed of calcium, phosphate and magnesium. The cause of deposition of calcium salt in the body tissue is not fully understood.

Metastatic calcifications occur in disorders of calcium and phosphorus metabolism, and are most likely to develop when the calcium-phosphorus product exceeds 70, hut may occur with normal levels [4]. In the case of chronic renal failure with secondary hyperparathyroidism, a significant association has been found between lung calcium content, elevated phosphate level and the calcium-phosphate product. No correlation has been observed with levels of parathormone, calcium, creatinine, protein, alkaline phosphatase or albumin, or with a history of parathyroidectomy. Moreover, no correlation was found with the duration of haemodialysis or with the type of dialysate [3].

Occasionally, metastatic lung calcification has been observed in the absence of supersaturation of extracellular fluid with calcium and phosphate ions [5]. Metastatic pulmonary calcifications have been shown to be present in $60-80 \%$ of autopsied haemodialysis patients, although rarely recognized during life [6], their extent is usually reflected in the survival of the patient Although many patients remain asymptomatic, some develop severe respiratory symptoms which are related to the extent of calcification. Restrictive lung diseases with progressive decrease in TL,CO, VC and hypoxaemia may be associated with rising levels of pulmonary calcium levels [3].

The predilection of metastatic calcification for the upper lung area may be due to the high ventilation/perfusion ratio in this region, creating high oxygen and low carbon dioxide levels. Consequently relative alkalinity 
favours deposition of calcium salt. Normally, $\mathrm{pH}$ at the apex of the lung reaches roughly 7.51 , whilst at the base it is $7.39[7,8]$.

Pathologically, lung metastatic calcification is preferentially located in the alveolar septa. Nevertheless, it can occur in pulmonary arteries and bronchial walls. In mild cases, calcium deposits may be present along the alveolar epithelial basement membrane and in the alveolar capillary walls without significant desmoplasia or septal thickening. Sometimes a foreign body giant cell reaction to the calcium can be found. Severe calcification tends to be associated with interstitial fibrosis [6].

The main differential diagnosis is lung dystrophic calcification. Dystrophic calcification consists of calcium deposition in dead cells or tissue damaged by infections (tuberculosis, fungal infections, chickenpox pneumonitis), silicosis, sarcoidosis, metastatic tumour, rheumatic mitral stenosis, microlithiasis and broncholithiasis or extensive bone malignancy [9]. The roentgenographic images are usually specific: and calcispherytes of alveolar microlithiasis; popcorn ball of hamartoma, etc.

The present case report is of interest for several reasons. To our knowledge, this is the second report of a progressive pulmonary calcification occurring in a transplant recipient with a normally functioning renal transplant [1]. The precise mechanism of pulmonary calcification remains unknown. As in the first description, this patient showed no increase in calcaemia, or phosphoraemia. The case confirms that chest radiography is not a sensitive tool for detecting pulmonary calcifications. In contrast to the benign course of pulmonary calcification in most patients, some fulminant pulmonary calcifications complicating renal transplantation or hypercalcaemia have been described. It is important to recognize such entities so as to correctly identify this potentially progressive and fatal cause of respiratory failure $[10,11]$.
Acknowledgement: The authors thank D. Warwick for her help in reviewing the manuscript.

\section{References}

1. Breitz HB, Sirotta PA, Nelp WB, Ott S, Figley MM. Progressive pulmonary calcification complicating successful renal transplantation. Am Rev Respir Dis 1987; 136: $1480-1482$.

2. Hartman TE, Müller NL, Primack SL, et al. Metastatic pulmonary calcification in patients with hypercalcemia. Am J Roentgenol 1994; 162: 799-802.

3. Sanders C, Franck MS, Rostand SG, et al. Metastatic calcification of the heart and lungs in end-stage renal disease. Am J Roentgenol 1987; 149: 881-887.

4. Stanbary SW, Lamb GA. Parathyroid function in chronic renal failure. $Q J$ Med 1966; 35: 1-23.

5. Neff M, Yalcin S, Gupta S, Berger H. Extensive metastatic calcification of the lung in azotemic patient. Am J Med 1974; 56: 103-109.

6. Conger JD, Hammond WS, Alfrey AC, Contiguglia SR, Stanford RE, Huffer WE. Pulmonary calcification in chronic dialysis patients: clinical and pathological studies. Ann Intern Med 1975; 83: 330-336.

7. West JB. Regional differences in blood flow and ventilation in the lung. In: Caro CG, ed. Advances in Respiratory Physiology. Baltimore, Williams \& Wilkins, 1966; pp. 198-254.

8. Jost RG, Sagel SS. Metastatic calcification in the lung apex. Am J Roentgenol 1979; 133: 1188-1190.

9. Mani TM, Lallemand D, Corone S, Mauriat P. Metastatic pulmonary calcifications after cardiac surgery in children. Radiology 1990; 174: 463-467.

10. Kuhlman JE, Ren HR, Hutchins GM, Fishman EK. Fulminant pulmonary calcification complicating renal transplantation: CT demonstration. Radiology 1989; 173: 459-460.

11. Margolin RJ, Addison TE. Hypercalcemia and rapidly progressive respiratory failure. Chest 1984; 86: 767-769. 